\title{
Reference value of Forced Oscillation Technique for healthy preschool children
}

\author{
Pinyapa Mukdjindapa, Wiparat Manuyakorn, Potjanee Kiewngam, Cherapat Sasisakulporn, Pisut Pongchaikul, \\ Wasu Kamchaisatian, Suwat Benjaponpitak
}

\begin{abstract}
Background: The reference values of Forced Oscillation Technique (FOT) parameters of the inspiratory and expiratory phase for preschool children have not yet been established.
\end{abstract}

Objective: To evaluate FOT measures in Thai healthy preschool children.

Methods: Preschool children, aged 3-6 years, were screened. Children who were positive for the International Study of Asthma and Allergies in Childhood (ISAAC) questionnaire for asthma, positive family history of allergic diseases, recent lower respiratory tract infections, and environmental tobacco smoke were excluded. FOT parameters, including resistance (Rrs), reactance (Xrs), frequency of resonance (Fres) and area of reactance (ALX), were measured.

Results: A total of 390 healthy children with the mean age of $5.1 \pm 0.9$ years were enrolled. FOT was successfully performed in 378 children (96.9\%). The mean (SD) for the whole breath (WB) resistance at $5 \mathrm{~Hz}(\mathrm{R} 5), 20 \mathrm{~Hz}(\mathrm{R} 20)$ and R5-20 were 11.49 (2.69) $\mathrm{cmH}_{2} \mathrm{O} / \mathrm{L} / \mathrm{s}, 9.46(2.19) \mathrm{cmH}_{2} \mathrm{O} / \mathrm{L} / \mathrm{s}$ and $2.02(0.82) \mathrm{cmH}_{2} \mathrm{O} / \mathrm{L} / \mathrm{s}$, respectively. The median (IQR) for WB reactance at 5Hx (X5), Fres and ALX were $-1.51(-2.37$ to -0.96$) \mathrm{cmH}_{2} \mathrm{O} / \mathrm{L} / \mathrm{s}, 11.17(8.50-15.65) \mathrm{Hz}$, and 7.53 (3.72-14.32) $\mathrm{cmH}_{2} \mathrm{O} / \mathrm{L} / \mathrm{s}$, respectively. Significantly difference in WB R5, R20, X5, Fres and ALX between male and female children were demonstrated. The expiratory phase R5, R20, R5-20 were significantly higher than those of the inspiratory phase $(p<0.001)$. There are significant correlations between the height and FOT parameters. Reference curve for the FOT parameters was generated based on height using the lambda-mu-sigma (LMS) method.

Conclusion: Reference curve of FOT parameters measured in healthy preschool children were demonstrated. Majority of preschool children could perform FOT method.

Key words: Respiratory resistance, Respiratory reactance, LMS method, Frequency of resonance, Area of reactance

\section{From:}

Division of Pediatrics Allergy and Immunology,

Department of Pediatrics, Faculty of Medicine Ramathibodi Hospital,

Mahidol University

\author{
Corresponding author: \\ Wiparat Manuyakorn \\ Division of Pediatrics Allergy and Immunology, \\ Department of Pediatrics, Faculty of Medicine Ramathibodi Hospital, \\ Mahidol University \\ Rama VI Rd, Ratchathewi, Bangkok 10400, Thailand \\ E-mail: mwiparat@hotmail.com
}

FOT is a modality based on the application of an external oscillatory signal in order to determine the mechanical response of the respiratory system. ${ }^{2}$ FOT requiring minimal patient cooperation makes it possible to evaluate the mechanical properties of the respiratory system in young children. ${ }^{3}$ Recently, its clinical application has spread worldwide with the expansion of commercially available broadband frequency FOT devices which are difference in the impulse signal and 
data processing. ${ }^{4}$ The results measured form difference FOT devices were relatively correlated but not exactly equivalent. ${ }^{5}$ Reference value of the impulse oscillometry system (IOS), one of the commercially available FOT, have been reported in Caucasian, ${ }^{6,7}$ Korean, ${ }^{8}$ Taiwanese preschool children. ${ }^{9}$ Recent reports have shown the reference value of the other commercial available FOT in Thai ${ }^{10}$ and Australian ${ }^{11}$ preschool children. All of the previous reports on the reference value of FOT derived from the analysis of the whole breath. There is no report on the reference value of the inspiratory and expiratory phase before. The present study was to determine the reference value of FOT parameters during inspiratory, expiratory phases and whole breath in preschool children.

\section{Methods \\ Subjects screening and enrollment}

A cross-sectional study was performed in healthy children aged between 3 to 6 years in kindergartens and primary school. All subjects were attending in 2 schools in Bangkok, Thailand and 7 schools in Nonthaburi, Thailand from May to September 2016.

Subjects with the following characteristics were excluded: (i) being at risk of, or identified with asthma, defined by physician diagnosis, history of wheezing, or positive screening for ISAAC (the International Study of Asthma and Allergies in Childhood) questionnaire; (ii) having personal history of allergic rhinitis or atopic dermatitis; (iii) having history condition of premature birth, low birth weight, or macrosomia (gestational age $<37$ weeks, birth weight $<2,500 \mathrm{~g}$ or $>4,000$ g); (iv) exposure to passive smoking in the family; (v) having abnormal body measurement (body weight and/or height was less than percentile 3 or more than percentile 97); (vi) identifying with recent upper respiratory tract infection in 4 weeks; (vii) having personal history of bronchitis, bronchiolitis, or pneumonia; (viii) having history of respiratory tract infection required hospitalization; (ix) having family history of allergic rhinitis or asthma; and (x) being diagnosed with other disease which may affecting lung function or FOT measurement including cardiovascular disease, pulmonary disease, thalassemia, cleft palate.

This study was approved by the ethics committee of Ramathibodi Hospital, Mahidol University ID 02-59-10, and date of approval March 3, 2016. Written informed consent was obtained from the parents of all participating children.

\section{Forced Oscillation Technique Measurement}

The measurements were performed using a commercially equipped FOT (MostGraph-02; Chest M.I., Co Ltd, Tokyo, Japan), and complied with the recommendation of the American Thoracic Society. ${ }^{1}$ Oscillatory signals generated by a loudspeaker at intervals of $0.25 \mathrm{~s}$ were applied to the respiratory system through the mouthpiece during tidal breathing at rest. The mouth pressure and flow signals were measured and calculated to obtain the Rrs and Xrs properties against the oscillatory frequencies ranging from 4 to $36 \mathrm{~Hz}$. FOT was performed during spontaneous tidal breathing. Children were asked to breathe through a mouthpiece that incorporated to a bacterial filter. The measurements were taken in upright position. The regular tidal breathing was performed with a nose-clip while technician supported the cheeks and lower jaw. During data acquisition, pressure and flow traces were graphically displayed in real time. Measurements were accepted when the tracings showed uninterrupted breathing during data acquisition. If swallowing, glottis closure, leaking around the mouthpiece, improper sealing with the nose clip, irregular breathing, or acute hyperventilation occurred, the measurement was discarded. If an apparent irregularity in the signal images were observed, the children were instructed for the breathing and re-examined. Results were acceptable if the coefficient of variation of at least 2 sets of data was less than $10 \%$. The measurements were considered acceptable only when the time segment chosen for analysis lasted for at least 20 seconds. Three to five technically acceptable measurements were performed. The best values of FOT measures were used for analysis. FOT parameters were expressed as the mean values during a respiratory cycle (whole-breath), inspiratory and expiratory phases. Rrs at 5 and $20 \mathrm{~Hz}$ (R5 and R20, respectively) and the difference between R5 and R20 (R5-20). Since low frequency oscillation frequencies are able to be transmitted more distally in the lungs. Rrs at $5 \mathrm{~Hz}$ (R5) represents the obstruction in the small and large airways airway while Rrs at $20 \mathrm{~Hz}$ (R20) reflects the obstruction of the large airways. The difference of resistance between low and high frequency (R5-20) or frequency dependence of resistance is increased if peripheral airway resistance increases. Xrs at $5 \mathrm{~Hz}$ (X5), which reflects elastic and inertial properties of the lung. Resonant frequency (Fres), where Xrs crosses zero and the elastic and inertial forces are equal in magnitude and opposite; and a low-frequency reactance area (ALX), which is an integral of $\mathrm{X} 5$ to Fres were recorded. Fres and ALX reflect changes in the degree of peripheral airway obstruction. ${ }^{3}$

\section{Statistical analysis}

Analysis were performed using STATA statistical software version 14 (Stata corp LP, Texus, USA). Descriptive statistical methods (median, mean \pm SD and frequency) were used to analyze the demographic data. Analysis of difference between groups were performed with chi-squared test. The continuous variables were compared using $t$ test. Correlation between respiratory parameters and weight or height were analyzed with Pearson's correlation. Stepwise multiple linear regression analysis was performed to identify the best predictor among various parameters of the FOT by using height, age, body weight, and gender as potential independent variables. Reference curve was generated using the lambda-mu-sigma (LMS) methods by $R$ program.

\section{Results}

2,944 children, aged 3-6 years, were screened. Children who were positive for ISAAC questionnaire for asthma or had a family history of allergy, recent lower respiratory tract infection, environmental tobacco smoke and abnormal physical examination were excluded. 390 children met the inclusion criteria. FOT was successfully performed in 378 (96.9\%) children (Figure 1). The mean age of the enrolled children was $5.1 \pm 0.9$ year. 180 children $(47.6 \%)$ were male. 


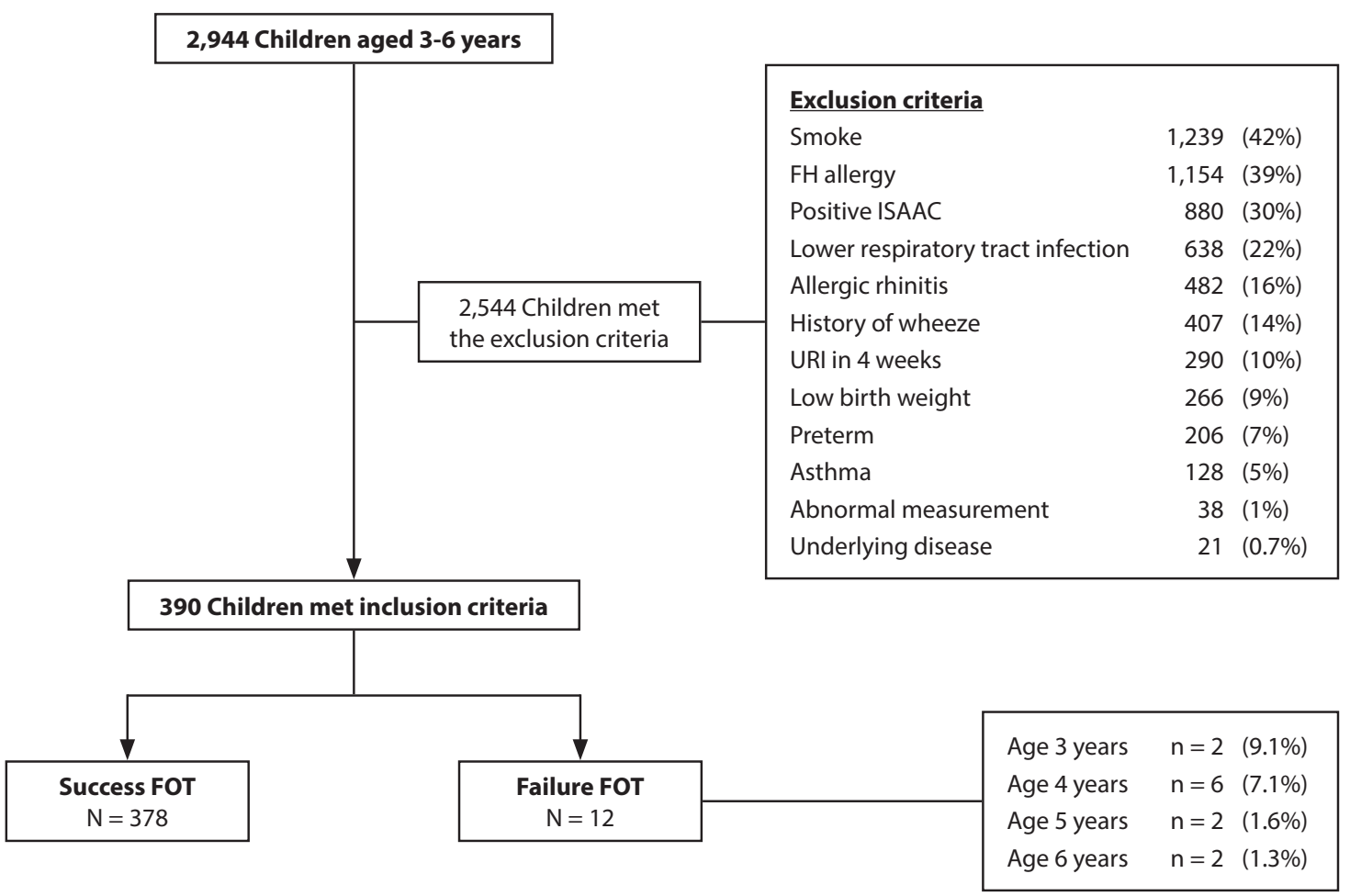

Figure 1. Selection of enrolled children.

Demographic characteristics of enrolled children were demonstrated in Table 1. The mean of the whole breath (WB), inspiratory (In) phase and expiratory (Ex) phase of R5, R20 R5-20, X5, Fres and ALX were demonstrated in Table 2. Significantly difference in WB R5, R20, X5, Fres and ALX between male and female children were demonstrated. The expiratory phase R5, R20, R5-20 were significantly higher than those of the inspiratory phase $(p<0.001)$ (Table 3$)$. There are modest correlations between the height and FOT parameters (Rrs, Xrs,
Fres and ALX) (Table 4). In stepwise regression analysis, the height was the strongest independent variable for the models of all FOT parameters. Since there was significant differences in FOT measures between male and female. The reference curve was generated according to sex. The reference curve for R5 and R20: WB, inspiratory phase and expiratory phase were demonstrated in Figure 2. As the child height increases, the resistances decrease in a linear manner. The reference curve for WB R5-20, ALX and Fres were demonstrated in Figure 3.

Table 1. Characteristics of the study population.

\begin{tabular}{|ccccc}
\hline & $\begin{array}{c}\text { Total } \\
(\mathbf{n}=\mathbf{3 7 8})\end{array}$ & $\begin{array}{c}\text { Male } \\
(\mathbf{n = 1 8 0})\end{array}$ & $\begin{array}{c}\text { Female } \\
(\mathbf{n}=\mathbf{1 9 8})\end{array}$ & p-value \\
\hline Age (years) & $5.1 \pm 0.93$ & $5.0 \pm 0.91$ & $5.1 \pm 0.94$ & 0.18 \\
\hline 3 & $22(5.8)$ & $11(5.6)$ & $11(6.1)$ & \\
\hline 4 & $84(22.2)$ & $48(24.2)$ & $36(20)$ & \\
\hline 5 & $121(32)$ & $69(34.8)$ & $52(28.9)$ & 0.060 \\
\hline 6 & $151(39.9)$ & $70(35.4)$ & $81(45)$ & 0.451 \\
\hline BW $(\mathrm{kg})$ & $18.79 \pm 3.61$ & $19.16 \pm 3.81$ & $18.46 \pm 3.4$ & \\
\hline Ht $(\mathrm{cm})$ & $111.9 \pm 7.79$ & $112.22 \pm 8.16$ & $111.62 \pm 7.45$ & \\
\hline $91-105$ & $70(18.5)$ & $35(17.7)$ & $35(19.4)$ & \\
\hline $106-120$ & $254(67.2)$ & $139(70.2)$ & $115(63.9)$ & 0.095 \\
\hline $121-136$ & $54(14.3)$ & $24(12.1)$ & $30(16.7)$ & \\
\hline BMI $\left(\mathrm{kg} / \mathrm{m}^{2}\right)$ & $14.93 \pm 1.81$ & $15.13 \pm 1.83$ & $14.76 \pm 1.78$ & \\
\hline $\mathrm{BSA}\left(\mathrm{m}^{2}\right)$ & $0.76 \pm 0.09$ & $0.77 \pm 0.1$ & $0.75 \pm 0.09$ & \\
\hline
\end{tabular}

Values presented as mean \pm SD. and N (\%), P-value corresponds to Independent's $t$ test. 
Table 2. Comparison FOT parameters between male and female preschool children

\begin{tabular}{|c|c|c|c|c|}
\hline & Total & Male & Female & $p$-value \\
\hline $\mathrm{R}_{\mathrm{WB}}\left(\mathrm{cmH}_{2} \mathrm{O} / \mathrm{L} / \mathrm{S}\right)$ & $11.49 \pm 2.69$ & $11.8 \pm 2.67$ & $11.2 \pm 2.69$ & $0.032^{\star}$ \\
\hline $\mathrm{R}_{\mathrm{Ex}}\left(\mathrm{cmH}_{2} \mathrm{O} / \mathrm{L} / \mathrm{S}\right)$ & $12.75 \pm 3.36$ & $13.09 \pm 3.36$ & $12.43 \pm 3.33$ & 0.054 \\
\hline $\mathrm{R}_{\mathrm{In}}\left(\mathrm{cmH}_{2} \mathrm{O} / \mathrm{L} / \mathrm{S}\right)$ & $10.23 \pm 2.3$ & $10.5 \pm 2.24$ & $9.98 \pm 2.33$ & $0.027^{*}$ \\
\hline $\mathrm{R} 20_{\mathrm{wB}}\left(\mathrm{cmH}_{2} \mathrm{O} / \mathrm{L} / \mathrm{S}\right)$ & $9.46 \pm 2.19$ & $9.71 \pm 2.2$ & $9.24 \pm 2.16$ & $0.039^{*}$ \\
\hline $\mathrm{R} 20_{\mathrm{Ex}}\left(\mathrm{cmH}_{2} \mathrm{O} / \mathrm{L} / \mathrm{S}\right)$ & $10.24 \pm 2.57$ & $10.48 \pm 2.54$ & $10.03 \pm 2.59$ & 0.090 \\
\hline $\mathrm{R} 20_{\mathrm{In}}\left(\mathrm{cmH}_{2} \mathrm{O} / \mathrm{L} / \mathrm{S}\right)$ & $8.69 \pm 1.93$ & $8.94 \pm 1.96$ & $8.46 \pm 1.87$ & $0.016^{*}$ \\
\hline $\mathrm{R} 5-20_{\mathrm{wB}}\left(\mathrm{cmH}_{2} \mathrm{O} / \mathrm{L} / \mathrm{S}\right)$ & $2.02 \pm 0.82$ & $2.09 \pm 0.77$ & $1.96 \pm 0.86$ & 0.120 \\
\hline $\mathrm{R} 5-20_{\mathrm{Ex}}\left(\mathrm{cmH}_{2} \mathrm{O} / \mathrm{L} / \mathrm{S}\right)$ & $2.5 \pm 1.11$ & $2.61 \pm 1.13$ & $2.4 \pm 1.08$ & 0.058 \\
\hline $\mathrm{R} 5-20_{\mathrm{In}}\left(\mathrm{cmH}_{2} \mathrm{O} / \mathrm{L} / \mathrm{S}\right)$ & $1.54 \pm 0.81$ & $1.56 \pm 0.77$ & $1.52 \pm 0.85$ & 0.593 \\
\hline $\mathrm{X}_{\mathrm{wB}}\left(\mathrm{cmH}_{2} \mathrm{O} / \mathrm{L} / \mathrm{S}\right)$ & $-1.79 \pm 1.24$ & $-1.92 \pm 1.34$ & $-1.66 \pm 1.12$ & $0.043^{*}$ \\
\hline $\mathrm{X}_{\mathrm{Ex}}\left(\mathrm{cmH}_{2} \mathrm{O} / \mathrm{L} / \mathrm{S}\right)$ & $-1.61 \pm 1.49$ & $-1.78 \pm 1.62$ & $-1.44 \pm 1.36$ & $0.028^{*}$ \\
\hline $\mathrm{X}_{\mathrm{In}}\left(\mathrm{cmH}_{2} \mathrm{O} / \mathrm{L} / \mathrm{S}\right)$ & $-1.97 \pm 1.28$ & $-2.06 \pm 1.38$ & $-1.88 \pm 1.18$ & 0.179 \\
\hline Fres $_{\mathrm{wB}}(\mathrm{Hz})$ & $12.4 \pm 5.02$ & $13 \pm 5.49$ & $11.85 \pm 4.49$ & $0.028^{*}$ \\
\hline Fres $_{\mathrm{Ex}}(\mathrm{Hz})$ & $12.61 \pm 6.41$ & $13.37 \pm 6.99$ & $11.91 \pm 5.77$ & $0.029^{*}$ \\
\hline $\operatorname{Fres}_{\mathrm{In}}(\mathrm{Hz})$ & $12.19 \pm 4.3$ & $12.63 \pm 4.62$ & $11.79 \pm 3.95$ & 0.060 \\
\hline $\mathrm{ALX}_{\mathrm{WB}}\left(\mathrm{cmH}_{2} \mathrm{O} / \mathrm{L} / \mathrm{S}\right)$ & $11.6 \pm 11.89$ & $13.17 \pm 13.02$ & $10.18 \pm 10.59$ & $0.016^{*}$ \\
\hline $\mathrm{ALX}_{\mathrm{Ex}}\left(\mathrm{cmH}_{2} \mathrm{O} / \mathrm{L} / \mathrm{S}\right)$ & $11.81 \pm 15.39$ & $14.02 \pm 17.2$ & $9.8 \pm 13.27$ & $0.008^{*}$ \\
\hline $\mathrm{ALX}_{\mathrm{In}}\left(\mathrm{cmH}_{2} \mathrm{O} / \mathrm{L} / \mathrm{S}\right)$ & $11.4 \pm 11.36$ & $12.31 \pm 11.88$ & $10.56 \pm 10.83$ & 0.135 \\
\hline
\end{tabular}

Values presented as mean $\pm \mathrm{SD}$. $P$-value corresponds to Independent's $t$ test. WB represent whole breath, In represent inspiratory phase and Ex represent expiratory phase.

Table 3. Correlations between FOT parameters and Height, BW and BMI

\begin{tabular}{|c|c|c|c|c|c|c|}
\hline & \multicolumn{2}{|c|}{ Height $(\mathrm{cm})$} & \multicolumn{2}{|c|}{ BW (kg) } & \multicolumn{2}{|c|}{ BMI $\left(\mathrm{kg} / \mathrm{m}^{2}\right)$} \\
\hline & $\mathbf{r}$ & $p$-value & $\mathbf{r}$ & $p$-value & $\mathbf{r}$ & $p$-value \\
\hline $\mathrm{R} 5_{\mathrm{WB}}$ & -0.339 & $<0.001^{*}$ & -0.168 & $0.001^{*}$ & 0.130 & $0.012^{*}$ \\
\hline $\mathrm{R}_{\mathrm{Ex}}$ & -0.278 & $<0.001^{*}$ & -0.122 & $0.018^{*}$ & 0.136 & $0.008^{\star}$ \\
\hline $\mathrm{R}_{\text {In }}$ & -0.389 & $<0.001^{*}$ & -0.217 & $<0.001^{\star}$ & 0.106 & $0.039^{*}$ \\
\hline $\mathrm{R} 20_{\mathrm{wB}}$ & -0.301 & $<0.001^{*}$ & -0.131 & $0.011^{*}$ & 0.146 & $0.005^{*}$ \\
\hline $\mathrm{R} 20_{\mathrm{Ex}}$ & -0.250 & $<0.001^{*}$ & -0.097 & 0.060 & 0.142 & $0.006^{*}$ \\
\hline $\mathrm{R} 20_{\text {In }}$ & -0.350 & $<0.001^{*}$ & -0.169 & $0.001^{*}$ & 0.141 & $0.006^{\star}$ \\
\hline $\mathrm{R} 5-20_{\mathrm{WB}}$ & -0.312 & $<0.001^{\star}$ & -0.203 & $<0.001^{\star}$ & 0.038 & 0.463 \\
\hline R5-20 ${ }_{\mathrm{Ex}}$ & -0.263 & $<0.001^{\star}$ & -0.144 & $0.005^{\star}$ & 0.081 & 0.114 \\
\hline $\mathrm{R} 5-20_{\text {In }}$ & -0.270 & $<0.001^{*}$ & -0.213 & $<0.001^{\star}$ & -0.035 & 0.503 \\
\hline $\mathrm{X} 5_{\mathrm{WB}}$ & 0.228 & $<0.001^{\star}$ & 0.069 & 0.181 & -0.149 & $0.004^{*}$ \\
\hline $\mathrm{X} 5_{\mathrm{Ex}}$ & 0.121 & $0.018^{*}$ & -0.015 & 0.776 & -0.160 & $0.002^{*}$ \\
\hline $\mathrm{X} 5_{\text {In }}$ & 0.298 & $<0.001^{\star}$ & 0.150 & $0.003^{*}$ & -0.101 & $0.049^{*}$ \\
\hline Fres $_{\mathrm{WB}}$ & -0.129 & $0.012^{*}$ & 0.051 & 0.320 & 0.224 & $<0.001^{*}$ \\
\hline Fres $_{\mathrm{Ex}}$ & -0.064 & 0.213 & 0.106 & $0.040^{*}$ & 0.236 & $<0.001^{*}$ \\
\hline Fres $_{\text {In }}$ & -0.207 & $<0.001^{*}$ & -0.038 & 0.464 & 0.171 & $0.001^{*}$ \\
\hline $\mathrm{ALX}_{\mathrm{WB}}$ & -0.163 & $0.001^{*}$ & -0.026 & 0.616 & 0.144 & $0.005^{*}$ \\
\hline $\operatorname{ALX}_{\mathrm{Ex}}$ & -0.080 & 0.123 & 0.036 & 0.489 & 0.147 & $0.004^{*}$ \\
\hline $\mathrm{ALX}_{\mathrm{In}}$ & -0.234 & $<0.001^{*}$ & -0.102 & $0.046^{*}$ & 0.103 & $0.046^{*}$ \\
\hline
\end{tabular}

Values presented as Correlation (r). $P$-value corresponds to Pearson's Correlation. WB represent whole breath, In represent inspiratory phase and Ex represent expiratory phase. 

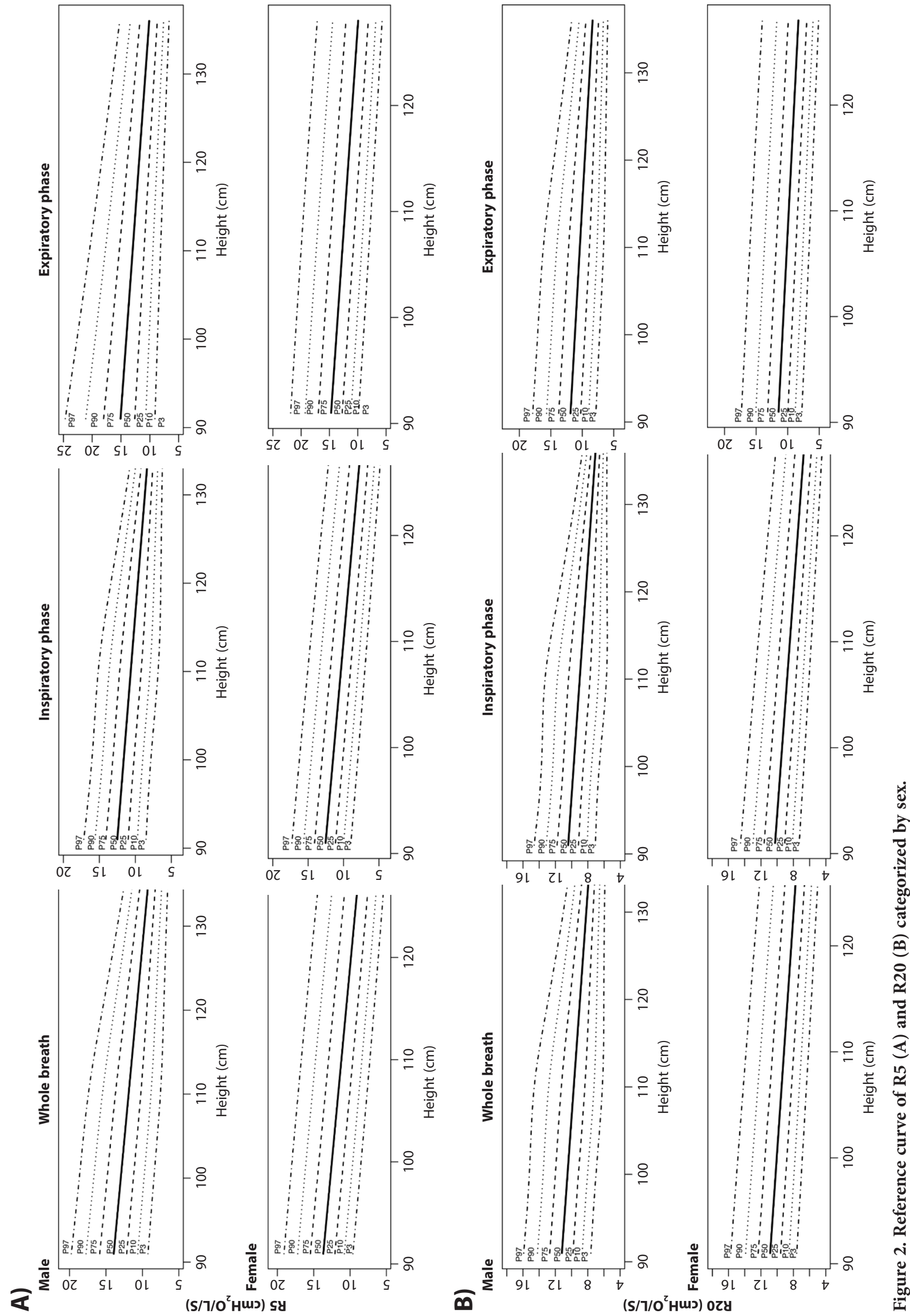

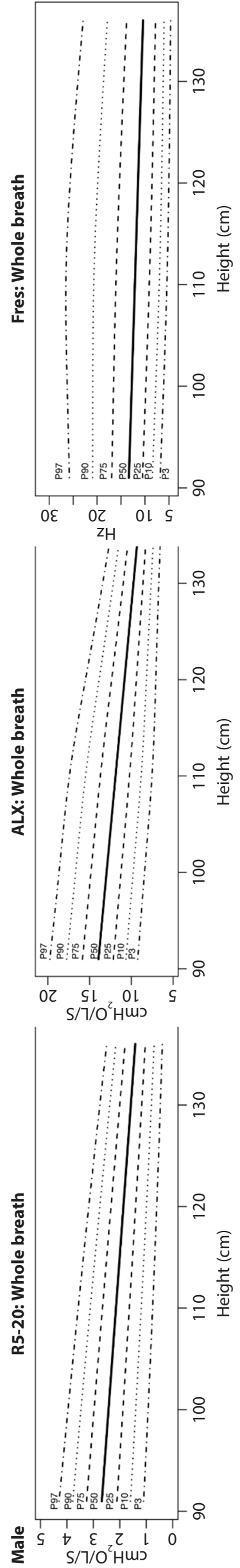
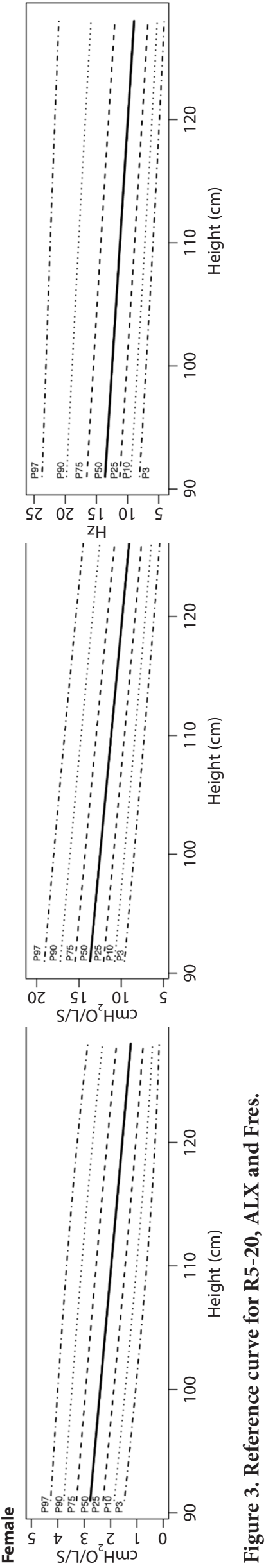

\section{Discussion}

In this study, we have demonstrated the reference value for FOT parameters including the whole breath, inspiratory phase and expiratory phase values in healthy Thai preschool children. The success rate for the valid FOT measurement was $97 \%$ of the enrolled children which is higher than previous report. ${ }^{6-8,10}$ The discrepancy in the successful rate may due to the differences in FOT techniques, differences in inclusion and exclusion criteria. We also used the same technician to instruct the enrolled children on how to perform the correct breathing before perform the FOT measurement and the majority of our enrolled children were 5 and 6 year old. We have shown the significant differences in the values of R5, R20, X5, Fres mad ALX between boy and girl. This finding is similar to previous report in Korean preschool children ${ }^{8}$ and in Japanese populations. ${ }^{12}$ Height was demonstrated to have the highest correlation with FOT parameters which is consistent with previous studies. ${ }^{67,9,10,13,14}$ Several previous reports have demonstrated the reference values of FOT parameters in preschool children using IOS. ${ }^{6,9,13,14}$ In the present study, we used a difference device, MostGraph-02. IOS and MostGraph-02 generate the same types of parameters including R5, R20, X5, Fres and ALX. It was shown that these two devices cannot generate the same value due to the differences in apparatus characteristics, oscillation signals and data processing and difference equation but the values were highly correlated. ${ }^{5} \mathrm{~A}$ study comparing between IOS and MostGraph have shown the higher reactance values from MostGraph than IOS. ${ }^{5}$ According to previous studies reported on the reference value of IOS machine in Asian children, at the height of $90 \mathrm{~cm}$, R5 value was reported ranging from $1.1-1.3 \mathrm{kPa} / \mathrm{L} / \mathrm{S} .{ }^{15}$ At the height of 90 $\mathrm{cm}$, our reference curve also demonstrates the similar range of result: R5 of $1.3 \mathrm{kPa} / \mathrm{L} / \mathrm{S}\left(13.5 \mathrm{cmH}_{2} \mathrm{O} / \mathrm{L} / \mathrm{S}\right)$. A recent study in Thai healthy children aged 3-7 years using The Quark i2m which is the different FOT device from the present study have reported the reference values for resistance at $6 \mathrm{~Hz}(\mathrm{R} 6)$, resistance at $8 \mathrm{~Hz}(\mathrm{R} 8)$, resistance at $10 \mathrm{~Hz}(\mathrm{R} 10)$ and reactance (Xrs) at 6, $8 \mathrm{~Hz}^{10}$ Since the difference in frequency used for FOT measurement and different in data processing. The FOT reference values from the present study are not equal to the previous reported value in Thai preschool children. ${ }^{10}$

Precise reference value for FOT measures in different height is essential in helping the diagnosis of respiratory disease especially in young children who could not perform spirometry correctly. FOT measurement was suggested to be more sensitive than spirometry in detecting subtle changes of lung function in children. ${ }^{3}$ However, several previous reports used linear or non-linear regression analysis for the reference value. $^{6-8,10,14}$ Since the variability of respiratory function measurements around the median is not uniform across different ages and heights, and there is a skewness in the distribution. As a result, regression analysis may not adequate to model the complex relationship between height and FOT result. The LSM method used in the preset study is a technique that is highly used for constructing children body sized related reference ranges for skewed data. ${ }^{16,17}$ The reference curve of IOS measured resistances for Japanese children aged 6-15 year using LMS method was shown the linear association of resistance with height similar to the present study. ${ }^{13}$ 
Our FOT measures reference curve of MostGraph for children aged 3-6 year should help in guidance for the interpretation of the result of FOT measure in young children. To interpret the results, initially it was advised to observe wheather Rrs and Xrs values are in the normal range. ${ }^{18}$ In diseases with peripheral obstruction, such as asthma, an increase of R5 and Fres and more negative of X5 values are observed..$^{19}$ In children with upper airway obstructive disorders, such as sleep apnea, an increased of R5 and R20 would be observed but there are no changes in the values of X5 and Fres. ${ }^{20}$ In children with restrictive lung disease, R5 and R20 should be within normal limits, and $\mathrm{X} 5$ is below the normal limit. ${ }^{20}$ However, further studies in children with respiratory disease are needed for the validation of our reference curve.

Our study is the first study to demonstrate the reference value of the inspiratory and expiratory phase of FOT parameters in preschool children using MostGraph. A recent study have demonstrated the reference value of MostGraph in healthy adult. ${ }^{12}$ The strength of our study is that the enrolled preschool children were healthy children. We extensively screened to exclude the population with personal history and family history of allergies, environmental tobacco smoke exposure. Furthermore, ISAAC questionnaire for asthma and allergic rhinitis were used to exclude children with asthma and allergic rhinitis. Children with histories of abnormal lung development and recent respiratory tract infection were excluded. The children with abnormal height and weight were also excluded because respiratory resistance was reported its inverses dependence with height. $6,7,9,10,13,14$ Obesity also affects FOT parameters. ${ }^{21}$ However, our result may not be able to elaborate to other Asian preschool children or other FOT devices.

\section{Conclusion}

FOT is a feasible pulmonary function test for young children. The reference curve of FOT parameters as predicted by height using LSM were demonstrated. The result of the present study will facilitate the application of this device in the determination of pulmonary function in preschool children and assist in the evaluation of respiratory disease especially asthma in young children.

\section{Conflict of interest}

The authors have no conflicts of interest to declare pertaining to this article.

\section{Acknowledgments}

This study was supported by a research grant from Faculty of Medicine Ramathibodi hospital, Mahidol University, Bangkok, Thailand (ID 025910). We would like to thank Ms. Dollapas Punpanich for the excellent contribution in statistical analysis.

\section{Authors' contributions}

$\mathrm{PM}, \mathrm{WK}, \mathrm{SB}$ and WM designed the study. PM and WM wrote the manuscript. PM, CS and PK contributed to data collection. PM, PP and WM performed the statistical analysis and interpretation of the results. WM edited the final manuscript. All authors read and approved the final manuscript.

\section{References}

1. Beydon N, Davis SD, Lombardi E, Allen JL, Arets HG, Aurora P, et al. An official American Thoracic Society/European Respiratory Society statement: pulmonary function testing in preschool children. Am J Respir Crit Care Med. 2007;175:1304-45.

2. Oostveen E, MacLeod D, Lorino H, Farre R, Hantos Z, Desager K, et al. The forced oscillation technique in clinical practice: methodology, recommendations and future developments. Eur Respir J. 2003;22:1026-41.

3. Skylogianni E, Douros K, Anthracopoulos MB, Fouzas S. The Forced Oscillation Technique in Paediatric Respiratory Practice. Paediatr Respir Rev. 2016;18:46-51.

4. Shirai T, Kurosawa H. Clinical Application of the Forced Oscillation Technique. Intern Med. 2016;55:559-66.

5. Tanimura K, Hirai T, Sato S, Hasegawa K, Muro S, Kurosawa H, et al. Comparison of two devices for respiratory impedance measurement using a forced oscillation technique: basic study using phantom models. J Physiol Sci. 2014;64:377-82.

6. Malmberg LP, Pelkonen A, Poussa T, Pohianpalo A, Haahtela T, Turpeinen M. Determinants of respiratory system input impedance and bronchodilator response in healthy Finnish preschool children. Clin Physiol Funct Imaging. 2002;22:64-71.

7. Shackleton C, Barraza-Villarreal A, Chen L, Gangell CL, Romieu I, Sly PD. Reference ranges for Mexican preschool-aged children using the forced oscillation technique. Arch Bronconeumol. 2013;49:326-9.

8. Park JH, Yoon JW, Shin YH, Jee HM, Wee YS, Chang SJ, et al. Reference values for respiratory system impedance using impulse oscillometry in healthy preschool children. Korean J Pediatr. 2011;54:64-8.

9. Lai SH, Yao TC, Liao SL, Tsai MH, Hua MC, Yeh KW, et al. Reference value of impulse oscillometry in taiwanese preschool children. Pediatr Neonatol. 2015;56:165-70.

10. Udomittipong K SW, Nimmannit A, Komoltri C. Respiratory Impedance Reference Values for Forced Oscillation Technique Predicted by Arm Span and Height in Thai Preschool Children. Pediatr Allergy Immunol Pulmonol 2017;30:97-102.

11. Hall GL, Sly PD, Fukushima T, Kusel MM, Franklin PJ, Horak F, Jr., et al. Respiratory function in healthy young children using forced oscillations. Thorax. 2007;62:521-6.

12. Abe Y, Shibata Y, Igarashi A, Inoue S, Sato K, Sato M, et al. Reference values of MostGraph measures for middle-aged and elderly Japanese individuals who participated in annual health checkups. Respir Investig. 2016;54: 148-55.

13. Hagiwara S, Mochizuki H, Muramatsu R, Koyama H, Yagi H, Nishida Y, et al. Reference values for Japanese children's respiratory resistance using the LMS method. Allergol Int. 2014;63:113-9.

14. Dencker M, Malmberg LP, Valind S, Thorsson O, Karlsson MK, Pelkonen A, et al. Reference values for respiratory system impedance by using impulse oscillometry in children aged 2-11 years. Clin Physiol Funct Imaging. 2006;26:247-50.

15. Galant SP, Komarow HD, Shin HW, Siddiqui S, Lipworth BJ. The case for impulse oscillometry in the management of asthma in children and adults. Ann Allergy Asthma Immunol. 2017;118:664-71.

16. Cole TJ, Stanojevic S, Stocks J, Coates AL, Hankinson JL, Wade AM. Age- and size-related reference ranges: a case study of spirometry through childhood and adulthood. Stat Med. 2009;28:880-98.

17. Stanojevic S, Wade A, Cole TJ, Lum S, Custovic A, Silverman M, et al. Spirometry centile charts for young Caucasian children: the Asthma UK Collaborative Initiative. Am J Respir Crit Care Med. 2009;180:547-52.

18. de Oliveira Jorge PP, de Lima JHP, Chong ESDC, Medeiros D, Sole D, Wandalsen GF. Impulse oscillometry in the assessment of children's lung function. Allergol Immunopathol (Madr). 2018.

19. Brashier B, Salvi S. Measuring lung function using sound waves: role of the forced oscillation technique and impulse oscillometry system. Breathe (Sheff). 2015;11:57-65

20. Yen FC, Behbehani K, Lucas EA, Burk JR, Axe JR. A noninvasive technique for detecting obstructive and central sleep apnea. IEEE Trans Biomed Eng. 1997;44:1262-8.

21. Assumpcao MS, Ribeiro JD, Wamosy RMG, Figueiredo F, Parazzi PLF, Schivinski CIS. Impulse oscillometry and obesity in children. J Pediatr (Rio J). 2018;94:419-24. 